Eixo Temático: Biologia Aplicada

\title{
ET-09-008 \\ INVESTIGAÇÃO ETNOFARMACOLÓGICA DO PERFIL HEMAGLUTINANTE E LECTÍNICO DO EXTRATO AQUOSO DA CASCA DO Stryphnodendron adstringens (Mart.) Coville
}

Nabuêr Francieli da Silva ${ }^{1}$, Gisele Nayara Bezerra da Silva ${ }^{1}$, Marina de Sá Leitão Câmara de Araújo $^{2}$, Rosângela Estevão Alves Falcão ${ }^{3}$

1Pós-graduandas no curso de Especialização em Saúde Pública pela Universidade de Pernambuco - Campus Garanhuns/PE.

${ }^{2} \operatorname{Prof}^{\mathrm{a}}$. Dr ${ }^{\mathrm{a}} \mathrm{UPE}$, Garanhuns/PE.

${ }^{3}$ Prof $^{\mathrm{a}}$. Dr ${ }^{\mathrm{a}} \mathrm{UPE}$, Garanhuns/PE.

http://dx.doi.org/10.21472/congrebio2016.et-09-008

\section{RESUMO}

A seleção de espécies vegetais por meio de levantamentos etnofarmacológicos configura uma importante via de triagem de bioatividade, através de informações das plantas advindas do saber popular, cujo valor farmacológico ainda não foi identificado. Entre as moléculas com ação terapêutica, destacam-se as lectinas, proteínas cuja ocorrência é predominante principalmente em espécies vegetais. O presente trabalho tem como objetivo avaliar o perfil hemaglutinante e a existência de lectinas no extrato aquoso da casca da espécie Stryphnodendron adstringens (Mart.) Coville, conhecida popularmente como barbatimão, investigando preliminarmente o seu perfil proteico no que tange o melhor $\mathrm{pH}$ para extração e a sua especificidade a carboidratos. Para realização do presente estudo foram feitas entrevistas semiestruturadas, através de conversas informais com os moradores das comunidades quilombolas do município de Garanhuns-PE, para seleção da espécie vegetal investigada. Posteriormente foram preparados extratos da casca em soluções tamponadas, para fins investigatórios. Os ensaios de hemaglutinação mostraram que os extratos da casca do $S$. adstrigens são capazes de aglutinar eritrócitos humanos, indicando a existência de lectinas, devido as propriedades hemaglutinantes dessas proteínas. Não foram encontrados, no entanto, especificidade para as frações proteicas estimadas, através da dosagem proteica e atividade hemaglutinante dos extratos, com os carboidratos: D-frutose, D-glicose, D-galactose, Dmaltose, D-sacarose e D-xilose na inibição da atividade hemaglutinante. Os ensaios mostraram ainda, que a fração proteica responsável pela hemaglutinação possui perfil ácido, sendo este o melhor pH para a sua extração. Diante das importantes funções biológicas atribuídas as lectinas, estas podem ser importantes ferramentas no diagnóstico e tratamento de muitas patologias.

Palavras-chave: Etnofarmacológicos; Lectinas; Stryphnodendron adstringens.

\section{INTRODUÇÃO}

A construção do conhecimento empírico medicinal pelos povos étnicos ao longo de milhares de anos, constituiu-se em uma importante fonte de consulta e resgate de saberes acerca do uso terapêutico das plantas envolvidas e relatadas por estas comunidades tradicionais, para possíveis análises e investigação de seus compostos, podendo ser utilizado para os mais diversos fins e nas mais distintas áreas.

Dentre os diversos grupos étnicos que detêm o conhecimento medicinal tradicional, estão as comunidades indígenas e quilombolas. Estas últimas têm origem remanescente de antigos grupos de escravos, no contexto da formação dos quilombos (MONEGO et al., 2010), o 
que pode ser acompanhado e averiguado em sua trajetória histórica, de onde mais tarde derivaria o nome atual destas comunidades.

O forte vínculo estabelecido por estas comunidades e o meio ambiente permitiu-lhes produzir e agregar conhecimentos empíricos sobre práticas alternativas relacionadas à saúde, se utilizando de espécies vegetais como eficazes agentes terapêuticos. A busca por substâncias ativas para a formulação de fármacos tem levado ao desenvolvimento de importantes estratégias, como ferramentas de investigação que atentem para exploração científica de agentes biologicamente ativos, em vias que representam verdadeiras fontes de novos compostos, como organismos vegetais de uso medicinal.

A Etnofarmacologia é um ramo da Etnobiologia/Etnobotânica que associa o estudo do conhecimento empírico das populações tradicionais junto a flora medicinal com estudos químicos/farmacológicos realizados em laboratórios (ELISABETSKY e SOUZA, 2010). Tratase de uma abordagem estratégica valiosa, que viabiliza a descoberta de novos fármacos, uma vez que o uso tradicional das plantas na medicina caseira pode ser considerado uma pré-triagem em relação a sua utilidade terapêutica em humanos (ELISABETSKY e SOUZA, 2010). Desta forma, as hipóteses levantadas sobre as ações dos compostos vegetais na terapêutica poderão ser testadas e averiguadas cientificamente, a partir de informações agregadas na medicina popular.

No elenco das espécies vegetais nativas úteis dos ecossistemas brasileiros, destaca-se Stryphnodendron adstringens (Mart.) Coville, conhecida vulgarmente como barbatimão, a qual sobressai-se tanto pelo seu valor econômico, quanto medicinal e farmacológico. Trata-se de uma espécie nativa do bioma cerrado, bastante empregada na medicina tradicional no tratamento de diversas afecções entre elas escorbúticas, gonorreia, hérnia, feridas hemorrágicas e diarreias (MACEDO et al., 2007).

A diversidade de princípios ativos nas plantas, comprovada por meio de inúmeros estudos, tem estimulado pesquisas para avaliação potencial de seus compostos. Entre as inúmeras moléculas biologicamente ativas, que podem ser encontradas em vegetais, cita-se as lectinas. Estas referem-se a um grupo heterogêneo de proteínas presentes em organismos vivos distintos, especialmente em plantas. A definição de lectinas coloca-as como "glicoproteínas que possuem a capacidade de se ligar especificamente aos monômeros de carboidratos presentes em um biopolímero" (ARRUDA, 2014).

Diversas são as funções e propriedades biológicas atribuídas as lectinas como reconhecimento de diferentes grupos sanguíneos humanos; indução da ativação de células de defesas; aglutinação celular; detecção, isolamento e caracterização de oligossacarídeos; identificação de glicoconjugados; podendo serem utilizadas no estudo da arquitetura da superfície celular, agentes no combate a diferentes patógenos, atividade antiviral e anticâncer (GONDIM, 2014).

Tendo em vista a vasta aplicabilidade das lectinas e o seu papel nos diferentes seres vivos, torna-se evidente a sua importância mediante a sua possível utilização como opções médicas terapêuticas e ferramentas valiosas em diversos estudos, justificando-se a necessidade de seu estudo e investigação em distintas fontes de seres vivos, para o seu isolamento e caracterização das suas funções biológicas.

\section{OBJETIVOS}

O presente trabalho tem como objetivo avaliar o perfil hemaglutinante e a possibilidade de lectinas no extrato aquoso da casca da espécie Stryphnodendron adstringens (Mart.) Coville, investigando preliminarmente o seu perfil proteico no que tange o melhor $\mathrm{pH}$ para extração e a sua especificidade a carboidratos. A partir da coleta de dados etnofarmacológicos acerca da espécie vegetal, nas comunidades quilombolas do munícipio de Garanhuns-PE. 


\section{MATERIAIS E MÉTODOS}

\section{Coleta de dados e identificação botânica}

A pesquisa foi introduzida com um estudo local nas comunidades Quilombolas do município de Garanhuns-PE, no que diz respeito aos relatos verbais referentes as práticas terapêuticas administradas por esses povos junto a flora medicinal. A partir das informações coletadas pôde-se fazer uma seleção de plantas daquela localidade, pertinentes à pesquisa, com base no conhecimento empírico dos recursos vegetais locais. As plantas de interesse medicinal nas comunidades quilombolas foram previamente selecionadas para estudos mais minuciosos, através de análises a serem realizadas em laboratório, com o intuito de investigar as atividades biológicas das ervas utilizadas no combate as várias afecções diárias e que, portanto apresentavam alguma ação terapêutica nas comunidades.

A inquirição etnofarmacológica se deu nas comunidades quilombolas do Castainho e Estrelas, onde foram realizadas quatro visitas nas áreas alvos de estudo ou respectivos locais de coleta do material vegetal. Nas duas primeiras visitas, realizou-se a coleta dos dados etnobotânicos e nas duas últimas a coleta da planta referida quanto ao uso medicinal pelos moradores, anteriormente entrevistados.

A espécie vegetal investigada Stryphnodrendon adstrigens (Mart.) Coville, conhecida vulgarmente como barbatimão, foi selecionada para o estudo utilizando como critério o conhecimento tradicional sobre o seu uso e aplicação na terapêutica local, bem como a parte da planta utilizada, adquirido em conversas informais e entrevistas semi-estruturadas com 14 moradores das comunidades quilombolas. Foram escolhidos os indivíduos de mais idade das comunidades, como mães e avós, que eram os moradores mais antigos, para dar maior confiabilidade às informações, sobre o conhecimento do uso medicinal das plantas locais. Para que os sujeitos pudessem participar desse estudo, foram elaborados os termos de consentimento e a submissão e aprovação do projeto junto ao Comitê de Ética em comprimento as exigências legais (CAAE $\mathrm{n}^{\mathrm{o}}$ 24906014.9.0000.5207).

As coletas dos dados etnobotânicos e do material botânico ocorreram entre os meses de 2014, ou conforme necessidade de reposição de extrato bruto no laboratório para a realização dos testes sequenciais no transcorrer da pesquisa. O material vegetal da espécie em questão representado pela casca, foi coletado com o auxílio de informantes das comunidades quilombolas que identificaram a planta vernaculamente em campo.

Para identificação taxonômica prévia da espécie realizou-se a consulta de material bibliográfico especializado, por meio do acesso a artigos científicos, baseando-se nas análises comparativas de suas características anatômicas e morfológicas.

Posteriormente foi produzida a exsicata com material vegetal contendo estruturas reprodutivas da planta para facilitar a identificação, e depositada no Instituto Agronômico de Pernambuco (IPA), para confirmação de sua nomenclatura científica por especialistas da área. As análises e todas as atividades desenvolvidas durante o estudo foram conduzidas nos laboratórios de Bioquímica e Biotecnologia da Universidade de Pernambuco (UPE), no Campus Garanhuns.

\section{Preparação do extrato aquoso da espécie coletada}

As cascas coletadas foram secas em estufa com circulação de ar a $40{ }^{\circ} \mathrm{C}$ por tempo suficiente até a sua secagem e trituradas em moinho elétrico de facas. $O$ pó da planta foi acondicionado em sacos plásticos, hermeticamente fechados, e mantidos sob refrigeração, até ser usado para produção de extratos.

$\mathrm{Na}$ obtenção dos extratos, os fragmentos vegetais das cascas do S. adstringens foram acondicionados em Erlenmeyer, sendo então submersos em três soluções respectivamente, tampão fosfato $0,15 \mathrm{M} \mathrm{em} \mathrm{pH} \mathrm{8,0,} \mathrm{tampão} \mathrm{citrato-fosfato} 0,15 \mathrm{M} \mathrm{pH} \mathrm{5,6} \mathrm{e} \mathrm{solução} \mathrm{salina} \mathrm{cloreto}$ de sódio $(\mathrm{NaCl})$ 0,15 M pH 7,0. 
Os extratos brutos foram preparados utilizando-se $10 \mathrm{~g}$ do material vegetal para $100 \mathrm{~mL}$ da solução tampão. Posteriormente, as amostras misturadas as soluções tamponadas foram levadas ao shaker para agitação over night.

Decorrido o tempo protocolado de 12 horas os extratos foram centrifugados a $4.000 \mathrm{rpm}$ por 15 minutos em temperatura ambiente, em seguida o sobrenadante denominado extrato aquoso, foi filtrado em gaze e armazenado em recipientes de vidro, onde foram rotulados com as respectivas informações: nome da planta, parte da planta utilizada, tampão, $\mathrm{pH}$, data do procedimento e então conservados sob refrigeração até a realização das análises.

\section{Preparo dos eritrócitos}

As amostras de sangue foram obtidas por meio de coletas em estudantes, doadores voluntários da unidade acadêmica da UPE, Campus Garanhuns, detentores dos respectivos grupos sanguíneos de interesse do sistema ABO. Após a coleta as amostras foram misturas com uma solução de ácido etilenodiamino tetra-acético (EDTA) anticoagulante em tubos falcon, para evitar a sua coagulação. Imediatamente o sangue foi centrifugado para precipitação das hemácias a $3.500 \mathrm{rpm}$ por 5 minutos, em temperatura ambiente. O sobrenadante (plasma sanguíneo) foi descartado com ajuda da pipeta de Pasteur e o volume do tubo falcon completado com solução cloreto de sódio $(\mathrm{NaCl} 0,15 \mathrm{M})$, junto ao precipitado.

As hemácias foram ressuspendidas delicadamente e centrifugadas nas mesmas condições até completadas o total de 4 lavagens. Ao final das lavagens o volume da massa de hemácias foi contabilizado, medindo-se o volume por estas ocupado nos tubos falcon, para mensurar a quantidade da solução de glutaraldeido em que as hemácias seriam glutarizadas, tendo-se em vista que estas deveriam estar concentradas a $1,5 \%$ na solução de glutaraldeido final. Após a determinação da quantidade da solução de glutaraldeido necessária, efetuou-se um novo cálculo para preparar a solução final de glutaraldeido a 1\% composta de 25 partes: 1 parte de glutaraldeido a $25 \%$ e 24 partes representada por uma solução A.

O preparo da solução A foi feito em gelo e definido pela decomposição das 24 partes em: 9 partes de $\mathrm{NaCl}$ a $0,15 \mathrm{M}, 1$ parte de $\mathrm{NaPO}_{4}$ a $0,15 \mathrm{M} \mathrm{pH} \mathrm{8,2} \mathrm{e} 5$ partes de água destilada. Em seguida foi adicionada a solução de glutaraldeido final preparada, o volume da massa de hemácias, retirando-se antes a diferença do volume destas da solução, anteriormente contabilizado.

As hemácias permaneceram na solução durante 20 minutos, sendo ressuspensas cuidadosamente durante esse período em que se encontravam dentro do gelo. Ao término do procedimento as hemácias foram novamente centrifugadas nas condições já descritas para eliminar o glutaraldeido, procedendo-se 5 lavagens em $\mathrm{NaCl}$. Finalizadas as lavagens a massa de hemácias foi diluída em $\mathrm{NaCl}$, permanecendo concentradas a 2,5\%, transferidas para recipientes de vidro e conservadas em freezer, para serem utilizadas durante os testes de atividade hemaglutinante com os extratos brutos aquosos.

\section{Detecção da atividade hemaglutinante (AH)}

A atividade hemaglutinante nos extratos da casca de S. adstringens, foi identificada utilizando-se eritrócitos humanos de diferentes grupos sanguíneos: A, B e O, previamente preparados pelo processo de glutarização acima descrito, com o propósito de averiguar aquele de maior susceptibilidade a hemaglutinação.

$\mathrm{O}$ ensaio para a avaliar a atividade hemaglutinante dos extratos foi realizado em placas de microtitulação com 8 fileiras de 12 poços cada, totalizando 96 poços, por meio de diluição serial. A diluição seriada ocorreu com o auxílio de pipetas, ponteiras estéreis e descartáveis, adicionando-se $50 \mu \mathrm{L}$ de soro $\mathrm{NaCl}$ em todos os poços do ensaio na placa, seguida de $50 \mu \mathrm{L}$ do extrato aquoso através de diluição seriada em cada poço, excetuando-se o primeiro poço, visto ser o poço controle, desprezando-se em seguida os últimos $50 \mu \mathrm{L}$ da amostra. Ocorrendo posteriormente a incubação com eritrócitos humanos em temperatura ambiente, por meio da adição de $50 \mu \mathrm{L}$ de sangue glutarizado. A leitura do ensaio foi efetuada após transcorrido exatos 45 minutos. 
Os resultados foram analisados visualmente, após o tempo protocolado, comparando-se com os respectivos controles, contendo somente a suspensão de eritrócitos, diluídos em solução salina, onde eventualmente iriam decantar.

Os testes foram realizados em triplicata e os resultados expressos em números de unidades hemaglutinantes (UH), determinados a partir do inverso do título da maior diluição, na base 2 que ainda apresentava aglutinação visível, seguida da soma da média aritmética dos ensaios da triplicata. As hemácias susceptíveis à hemaglutinação pelos extratos, foram utilizadas para os ensaios de inibição por carboidratos.

\section{Dosagem de proteínas}

As concentrações relativas de proteínas nos extratos foram estimadas pelo kit de detecção de proteínas (Pierce BCA Protein Assay Kit), utilizando-se curva de calibração com diferentes concentrações de proteína albumina (padrão) e absorbância em $562 \mathrm{~nm}$. A quantidade de reagente necessária para quantificar as proteínas presentes nos extratos, foi calculada conforme o número de amostras (extratos) a serem dosadas.

O doseamento de proteínas dos respectivos extratos, foi realizado em placas de microtitulação, adicionando-se $25 \mu \mathrm{L}$ de extrato em triplica, seguida da adição de $200 \mu \mathrm{L}$ de reagente as amostras. Prontamente foram incubadas em shaker a $37^{\circ} \mathrm{C}$ por 30 minutos, e levadas ao leitor de placas de microtitulação para contabilização das proteínas, em leitura a 562 nm de absorbância.

\section{Atividade hemaglutinante específica (AHE)}

O resultado da atividade hemaglutinante específica foi determinado, a partir da subtração do valor de " $x$ " encontrado na curva de calibração da média da dosagem de proteínas encontrada nos extratos aquosos, dividindo-se em seguida a mesma pelo valor de " $y$ " da curva, resultando na quantidade de proteínas em $\mathrm{mg} / \mathrm{mL}$. Assim, a atividade hemaglutinante específica foi calculada aplicando-se a seguinte fórmula: AHE = atividade hemaglutinante $(\mathrm{AH})$ / proteínas $\mathrm{mg} / \mathrm{mL}$.

\section{Estabilidade ao pH}

Para verificação da estabilidade proteica dos extratos frente a variante $\mathrm{pH}$, foram produzidos novos extratos brutos aquosos a $10 \%$, conforme metodologia já descrita. Os novos extratos foram preparados em diferentes tampões, submetendo-os a valores distintos de $\mathrm{pH}$ em cada tampão utilizado respectivamente: tampão acetato $\mathrm{pHs} 3,0 ; 3,5 ; 4,0 ; 4,5 ; 5,0$ e tampão fosfato pHs 5,$5 ; 6,0 ; 6,5 ; 7,0 ; 7,5 ; 8,0$ e 8,5. Em seguida, procedeu-se a atividade hemaglutinante (AH), dosagem proteica e atividade hemaglutinante específica (AHE) em cada um dos extratos nos respectivos pHs.

\section{Inibição da Atividade Hemaglutinante}

Os ensaios de inibição da atividade hemaglutinante foram realizados em placas de microtitulação, em que soluções inibitórias compostas de diferentes carboidratos, D-frutose, Dglicose, D-galactose, D-maltose, D-sacarose e D-xilose, foram testadas em sua habilidade em inibir a hemaglutinação ou a precipitação de carboidratos na superfície das hemácias pela possível lectina existente no extrato da referida espécie vegetal investigada.

$\mathrm{O}$ teste consistiu na solubilização das amostras inibitórias em $\mathrm{NaCl} 0,15 \mathrm{M}$. Cada amostra de carboidrato foi diluída em $1 \mathrm{~mL}$ de $\mathrm{NaCl}$ (tubo I), retirando-se em seguida $800 \mu \mathrm{L}$ e acrescidos $800 \mu \mathrm{L}$ de $\mathrm{NaCl}$ (tubo II). Após o preparo das soluções inibitórias e suas diluições, foram adicionadas $50 \mu \mathrm{L}$ da solução inibitória do tubo II em todos os poços do ensaio, exceto o poço 2 , onde fora acrescido $50 \mu \mathrm{L}$ da solução do tubo I com o dobro da concentração.

Logo após, a partir do poço sem diluição foram adicionados $50 \mu \mathrm{L}$ do extrato que apresentou melhor atividade hemaglutinante específica (AHE), fazendo diluição serial. Aguardado a incubação de 15 minutos para interação da possível lectina do extrato aquoso com o inibidor, foram adicionados $50 \mu \mathrm{L}$ da amostra de eritrócitos glutarizados do grupo sanguíneo 
$\mathrm{O}$, em todos os poços do ensaio. A placa foi então, mantida em repouso durante 45 minutos, em temperatura ambiente, para efetuação da leitura. A atividade inibitória foi identificada pela diminuição da $\mathrm{AH}$ da amostra (extrato aquoso) na presença do inibidor (carboidrato).

\section{RESULTADOS E DISCUSSÃO}

A hemaglutinação dos diferentes eritrócitos humanos frente aos extratos da casca do $S$. adstringens, ocorreu na presença de ambos os extratos preparados nos tampões iniciais testados: fosfato $0,15 \mathrm{M}$ em pH 8,0, citrato-fosfato $0,15 \mathrm{M} \mathrm{pH} \mathrm{5,6} \mathrm{e} \mathrm{solução} \mathrm{cloreto} \mathrm{de} \mathrm{sódio}(\mathrm{NaCl}) 0,15$ $\mathrm{M} \mathrm{pH} 7,0$, entretanto os melhores resultados expressos, foram obtidos para o tipo sanguíneo $\mathrm{O}$ e solução tampão fosfato. O ensaio de hemaglutinação possibilita a detecção de lectinas, devido a habilidade destas proteínas em induzir o fenômeno de aglutinação celular.

A média da atividade hemaglutinante nesse tipo sanguíneo e tampão foi de 8.388 .608 unidades hemaglutinantes (UH), para $236.000 \mathrm{UH}$ tampão citrato-fosfato e $32.768 \mathrm{UH}$ no tampão $\mathrm{NaCl}$, apresentando menor atividade hemaglutinante, portanto no tampão $\mathrm{NaCl}$. Esse resultado sugere que proteínas da classe das lectinas podem estar presentes nos extratos aquosos da espécie vegetal investigada, visto que, a especificidade das lectinas por carboidratos na superfície das hemácias, permiti-nos inferir ou detectar a possível existência dessas biomoléculas em diferentes fontes de seres vivos, através de ensaios de hemaglutinação.

Após a realização da dosagem proteica e atividade hemaglutinante específica (Tabela 1) dos extratos em questão, foi possível verificar que os melhores valores resultantes das respectivas atividades, se encontravam nos extratos preparados em solução tamponada Citratofosfato $\mathrm{pH} 5,6$, enfatizando o perfil ácido das frações proteicas envolvidas na hemaglutinação. Reafirmando deste modo, a possível existência de proteínas da classe lectinas nos extratos da espécie S. adstringens.

Tabela 1. Resultados da atividade hemaglutinante específica dos extratos aquosos da casca de barbatimão, nos tampões iniciais.

\begin{tabular}{|c|c|c|}
\hline Planta & Tampão & Média da atividade hemaglutinante específica \\
\hline \multirow{3}{*}{ Barbatimão (casca) } & Citrato-fosfato & $52.27 \mathrm{UH} / \mathrm{mg}$ \\
\cline { 2 - 3 } & $\mathrm{NaCl}$ & $7.09 \mathrm{UH} / \mathrm{mg}$ \\
\cline { 2 - 3 } & Fosfato & $2.04 \mathrm{UH} / \mathrm{mg}$ \\
\hline
\end{tabular}

Quanto ao perfil proteico verificado na estabilidade ao $\mathrm{pH}$, com os novos extratos no tampão acetato (pH: 3,$0 ; 3,5 ; 4,0 ; 4,5 ; 5,0)$ e tampão fosfato (pH: 5,5; 6,0;6,5; 7,0; 7,5; 8,0; $8,5)$, foi possível detectar maior ocorrência de proteínas em $\mathrm{mg} / \mathrm{ml}$, nos extratos aquosos de $S$. adstringens do $\mathrm{pH}$ 3,0 ao 4,0 (Figura 1), sem mudanças muito significativas nas quantidades das concentrações de proteínas, até o $\mathrm{pH}$ 6,0, ocorrendo pequenas oscilações entretanto, nas concentrações dos demais pHs. Os resultados expressos no gráfico para atividade hemaglutinante específica (Figura 2), mostram grandes variações, no entanto, conforme as mudanças nos valores de $\mathrm{pH}$. As variações de $\mathrm{pH}$, onde existe melhor atividade hemaglutinante específica encontram-se no $\mathrm{pH} \mathrm{3,0}$ ao 5,5, ocorrendo redução da atividade hemaglutinante específica nos valores de $\mathrm{pH}$, posteriores ao $\mathrm{pH} 5,5$. 


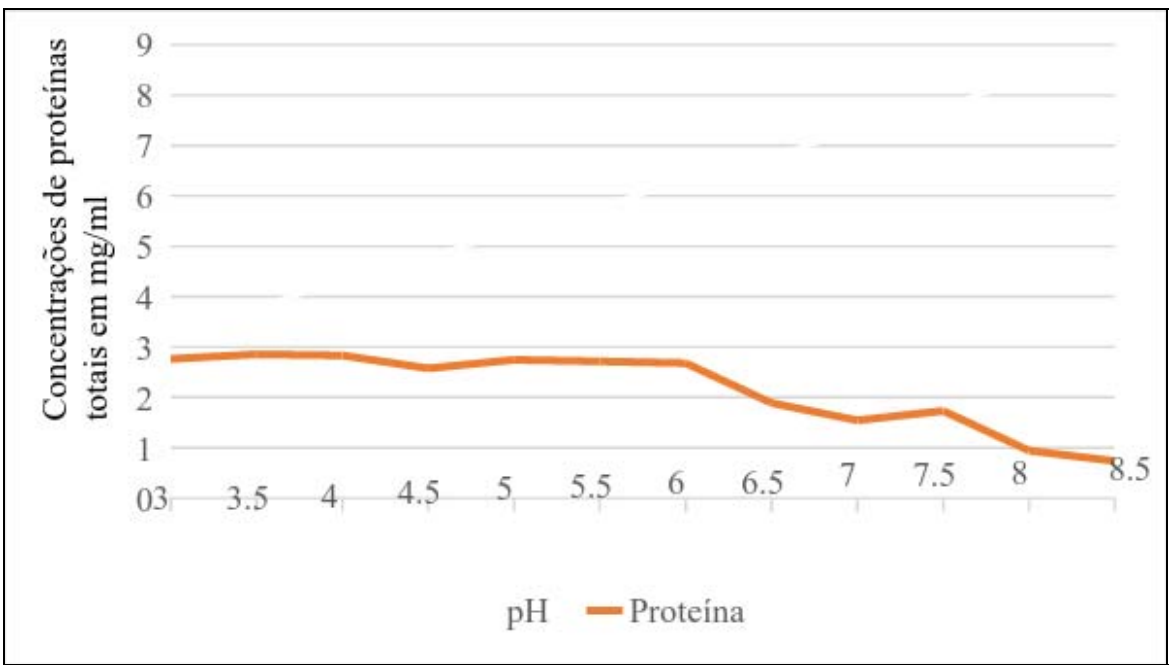

Figura 1. Resultado da variação quantitativa proteica nos extratos aquosos da casca de barbatimão, frente a variante $\mathrm{pH}$.

Os resultados dos ensaios (Figura 1), mostram que as concentrações de proteínas presentes nos extratos se mantêm estáveis, sem grandes oscilações ou quedas bruscas, frente a variante $\mathrm{pH}$, enquanto a atividade hemaglutinante específica (Figura 2) permanece em constância do $\mathrm{pH} \mathrm{3,0}$ ao 4,5, declinando posteriormente ao $\mathrm{pH} 4,5$. A partir do $\mathrm{pH} \mathrm{5,5}$ ao 6,0 a atividade hemaglutinante específica sofre uma queda brusca, declinando sucessivamente até o pH 8,5. O que permiti-nos inferir que a fração proteica nos extratos aquosos responsável pela atividade hemaglutinante, possui perfil ácido, desempenhando melhor atividade proteica nos pHs 3,0;3,5; 4,0 e 4,5 (Figura 2), sendo estes portanto, os melhores pHs para extração da proteína investigada.

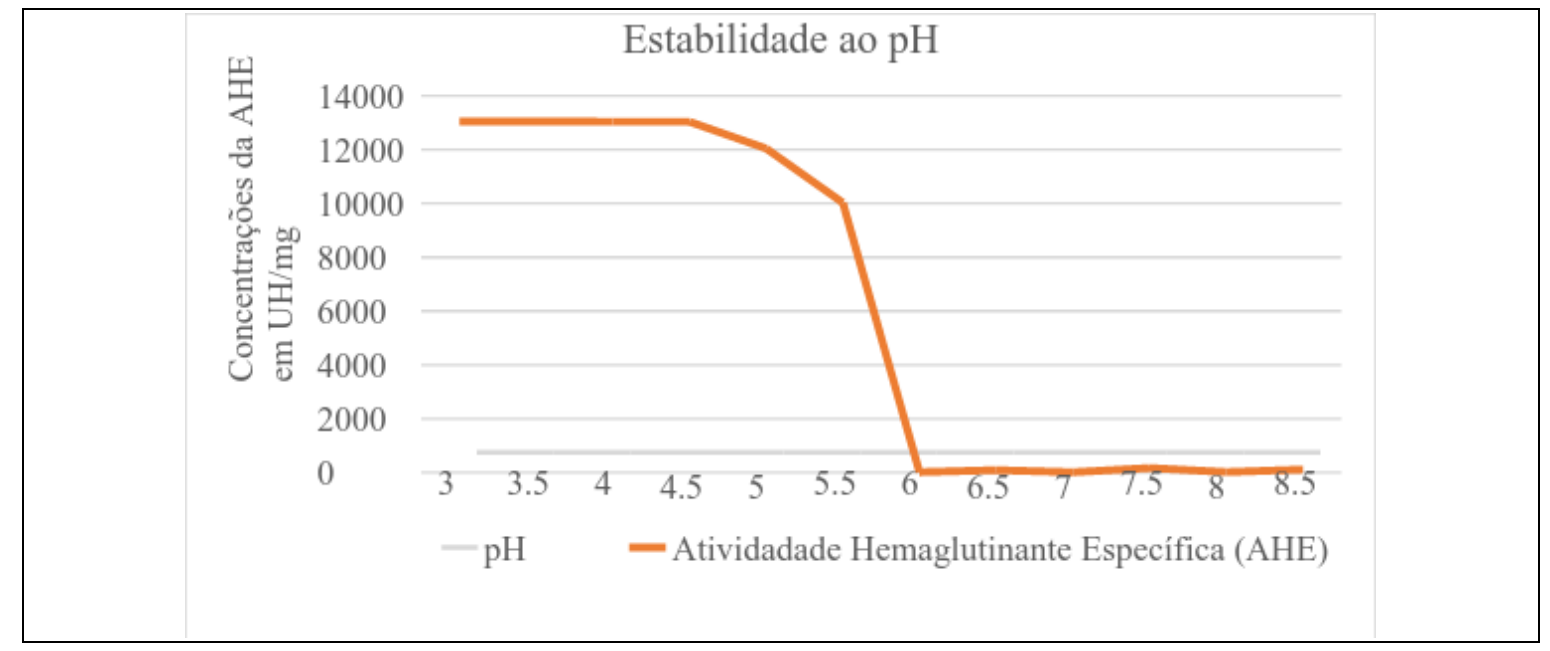

Figura 2. Resultado da atividade hemaglutinante específica, frente a variante $\mathrm{pH}$.

Considerando os resultados de inibição da atividade hemaglutinante com os eritrócitos humanos do tipo sanguíneo O e os seis tipos de carboidratos: D-frutose, D-glicose, D-galactose, D-maltose, D-sacarose e D-xilose testados, foi possível observar para a espécie S. adstrigens, 
que a glicose não foi capaz de inibir a atividade hemaglutinante dos extratos, produzidos em tampão acetato $\mathrm{pH}$ 3,0 (Figura 3, poços 2-12), $\mathrm{pH}$ em que a espécie apresentou maior atividade hemaglutinante específica (Figura 2). Resultados similares foram obtidos na presença de frutose, sacarose, galactose, maltose e xilose, indicando que esses carboidratos não inibem a atividade hemaglutinante das possíveis lectinas de $S$. adstringens (Figuras: 4, 5, 6, 7, 8; poços 212). O que nos faz concluir que a possível lectina existente no extrato aquoso do $S$. adstringens, não possui afinidade ou sítios de ligação para nenhum dos carboidratos testados. Sendo necessário, entretanto a realização de mais ensaios inibitórios da atividade hemaglutinante com outros açucares para definição do perfil proteico dos extratos, quanto a sua afinidade por carboidratos.

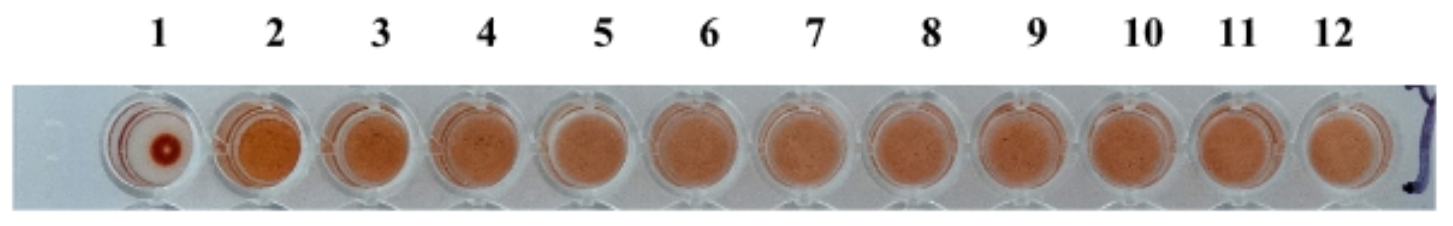

Figura 3. Ensaio de inibição da atividade hemaglutinante no extrato aquoso do Strynodendron adstringens, em tampão acetato $\mathrm{pH} 3,0$, utilizando eritrócitos humanos do tipo sanguíneo $\mathrm{O}$, na presença de glicose. Legenda: 1- poço controle: eritrócito + glicose; 2- poço com o dobro da concentração: glicose + extrato do S. adstringens + eritrócito e 2 - 12: diluição serial.

Dos vários trabalhos publicados na literatura referentes a espécie S. adstrigens, não foram encontrados registros de estudos, que identificassem a presença de lectinas para essa espécie. Entretanto, algumas publicações comprovam a existência dessa biomolécula em outras espécies, da mesma família. De acordo com Silva-López e Santos (2015), lectinas têm sido isoladas e purificadas para diversas espécies do gênero Bauhiania, da família Fabaceae. Nesse gênero estão incluídas mais 300 espécies, com ampla distribuição nas florestas tropicais e subtropicais. 


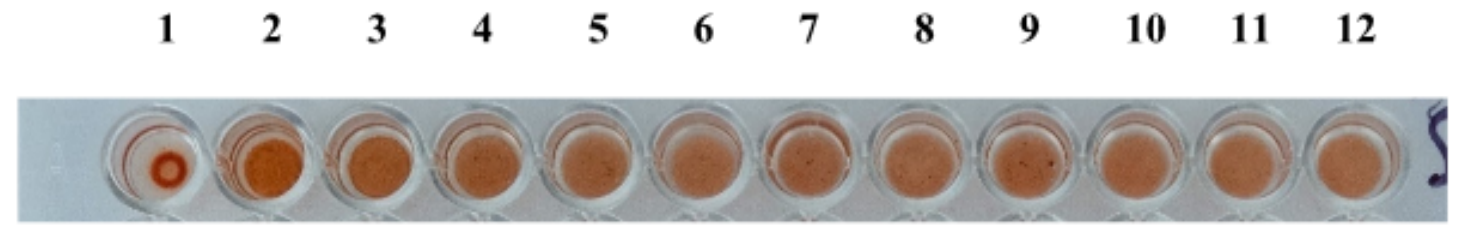

Figura 4. Ensaio de inibição da atividade hemaglutinante no extrato aquoso do Sthyphnodendron adstringens, em tampão acetato $\mathrm{pH}$ 3,0, utilizando eritrócitos humanos do tipo sanguíneo $\mathrm{O}$, na presença de frutose. Legenda: 1- poço controle: eritrócito + frutose; 2- poço com o dobro da concentração: frutose + extrato do S. adstringens + eritrócito e 2 - 12: diluição serial.

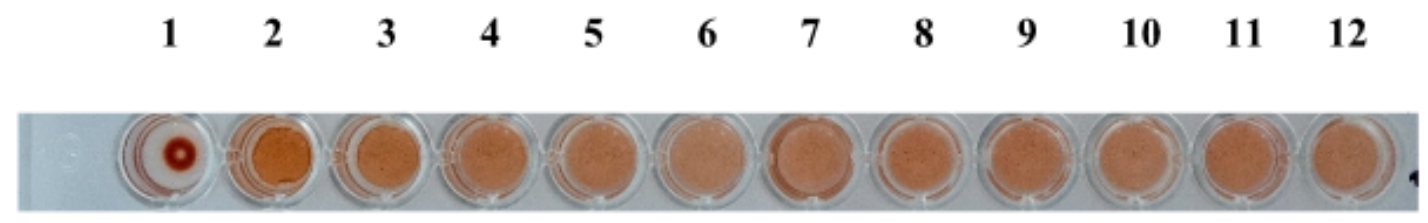

Figura 5. Ensaio de inibição da atividade hemaglutinante no extrato aquoso do Stryphnodendron adstringens, em tampão acetato $\mathrm{pH}$ 3,0, utilizando eritrócitos humanos do tipo sanguíneo $\mathrm{O}$, na presença de sacarose. Legenda: 1- poço controle: eritrócito + sacarose; 2- poço com o dobro da concentração: sacarose + extrato do S. adstringens + eritrócito e 2 - 12: diluição serial. 


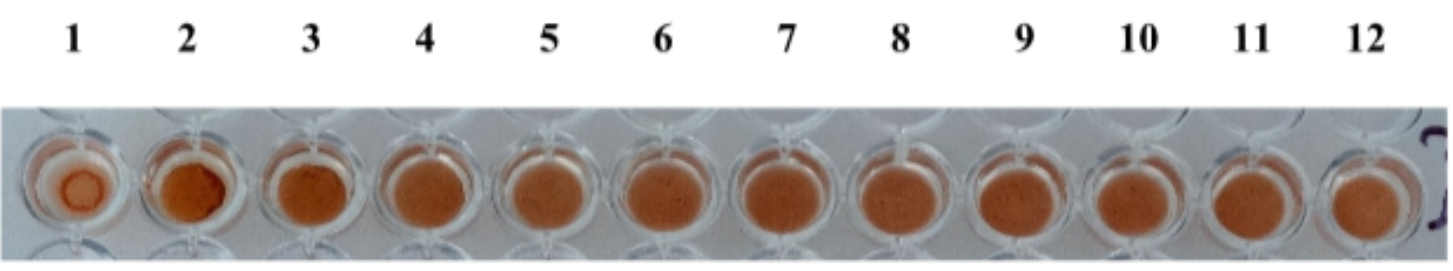

Figura 6. Ensaio de inibição da atividade hemaglutinante no extrato aquoso do Strynodendron adstringens, em tampão acetato $\mathrm{pH} 3,0$, utilizando eritrócitos humanos do tipo sanguíneo $\mathrm{O}$, na presença de galactose. Legenda: 1- poço controle: eritrócito + galactose; 2- poço com o dobro da concentração: galactose + extrato do $S$. adstringens + eritrócito e 2 - 12: diluição serial.

\section{$\begin{array}{llllllllllll}1 & 2 & 3 & 4 & 5 & 6 & 7 & 8 & 9 & 10 & 11 & 12\end{array}$}

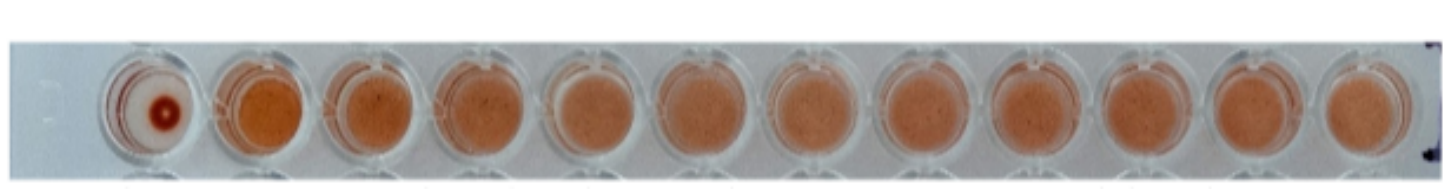

Figura 7. Ensaio de inibição da atividade hemaglutinante no extrato aquoso do Stryphnodendron adtringens, em tampão acetato $\mathrm{pH} 4,0$, utilizando eritrócitos humanos do tipo sanguíneo $\mathrm{O}$, na presença de maltose. Legenda: 1- poço controle: eritrócito + maltose; 2- poço com o dobro da concentração: maltose + extrato do S. adstringens + eritrócito e 2 - 12: diluição serial. 


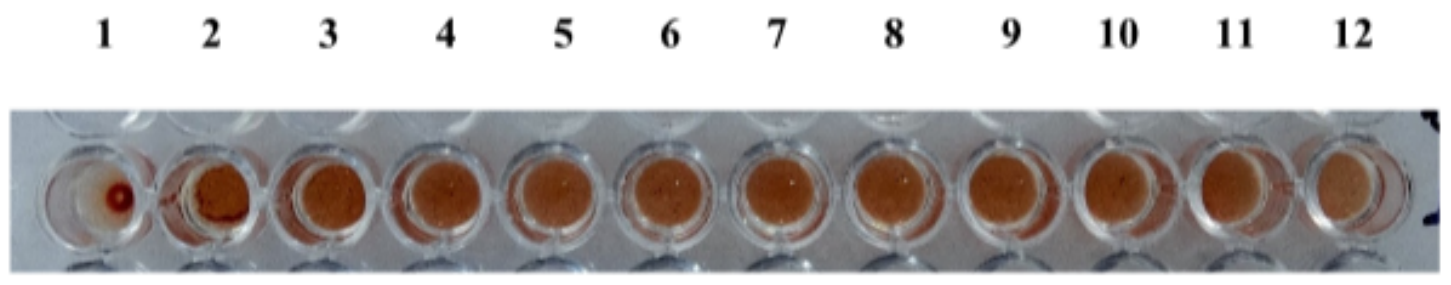

Figura 8. Ensaio de inibição da atividade hemaglutinante no extrato aquoso do Stryphnodendron adstringens, em tampão acetato $\mathrm{pH} 3,0$, utilizando eritrócitos humanos do tipo sanguíneo $\mathrm{O}$, na presença de xilose. Legenda: 1- poço controle: eritrócito + xilose; 2- poço com o dobro da concentração: xilose + extrato do $S$. adstringens + eritrócito e 2 - 12: diluição serial.

Adicionalmente, estudos como o de Pereira et al. (2014) têm evidenciado a presença dessas proteínas em várias espécies da família Fabaceae, incluindo: Caesalpinia ferrea Mart (pau-ferro), Parkia platycephala Benth. (visgueiro) e Copaifera langsdorffii Desf. (pau-d'óleo).

$\mathrm{O}$ interesse pelo isolamento e caracterização estrutural e funcional dessas proteínas na família Fabaceae, dar-se pelo fato de, segundo Vargas (2005), as lectinas estarem presentes, em sua maioria, nas plantas da família Fabaceae.

Vários estudos experimentais confirmam as observações etnofarmacológicas, para $S$. adstringens, quanto as suas propriedades terapêuticas atribuídas pela medicina tradicional. A avaliação da atividade antimicrobiana do extrato bruto hidroalcóolico das cascas de $S$. adstringens, conforme resultados obtidos por Soares et al. (2008), apresentou significativa ação antimicrobiana frente a diferentes cepas patogênicas da flora bucal: Enterococcus faecalis, Streptococcus sanguinis, Streptococcus mitis, Streptococcus mutans, Streptococcus sobrinus e Lactobacillus casei. Sugerindo o uso do extrato de barbatimão como auxiliar no combate a cárie dentária (SOARES et al., 2008).

Os resultados dos vários trabalhos acima mencionados revelam importantes indícios para a prospecção em $S$. adstringens de novas moléculas com atividades biológicas. Convém ressaltar ainda, que a maioria das moléculas isoladas em laboratório, que possuem algum princípio ativo e são reproduzidas através de síntese por modernas técnicas laboratoriais, provém de plantas (FIEDLER et al., 2008). Assim, a bioprospecção de novas biomoléculas a partir da sua investigação em fontes vegetais, configura-se como uma alternativa promissora na descoberta e desenvolvimento de novas substâncias com ação terapêutica, aplicáveis tanto na biotecnologia como na síntese de fitoterápicos de maior eficiência. 
A partir dos resultados apresentados das atividades realizadas com os extratos aquosos de $S$. adstringens, sugere-se que a espécie em estudo apresenta proteínas pertencente à classe das lectinas. No entanto, ensaios para caracterização das frações proteicas que apresentaram atividade hemaglutinante, como a sua purificação em cromatografia de coluna e posterior eletroforese visando o isolamento da proteína alvo, são necessários e indispensáveis para a confirmação dos resultados preliminares encontrados com o presente estudo.

\section{CONCLUSÕES}

A espécie Stryphnodendron adstringens mostrou ser um potencial promissor, como possível fonte de lectinas, diante dos resultados preliminares encontrados com o presente estudo, sem registros anteriores na literatura a respeito da existência de lectinas nesta espécie, podendo este trabalho ser base de apoio para consultas de novos estudos na área de lectinas, especificamente aqueles que venham a envolver a espécie em questão, devido a escassez de estudos nesta área, com $S$. adstringens. Os resultados encontrados indicam que, a fração proteica dos extratos responsáveis pela aglutinação de eritrócitos humanos tipo $\mathrm{O}$, podem tratarse de proteínas do tipo lectinas. Desta forma, as diferentes atividades biológicas atribuídas e desempenhadas pelas lectinas poderão permitir que estas possam ser usadas como uma ferramenta útil no diagnóstico e tratamento de muitas doenças.

\section{AGRADECIMENTOS}

As professoras $\operatorname{Dr}^{\mathrm{a}}$ Marina Araújo e Dr ${ }^{\mathrm{a}}$ Rosângela Falcão, orientadoras deste trabalho, pelos seus conhecimentos, atenção, apoio e boa vontade.

Aos moradores das comunidades quilombolas do município de Garanhuns-PE, pela disposição em nos atender e pela calorosa recepção nas visitas a campo, e partilha do seu valiosíssimo conhecimento empírico que serviu de estudo para o presente trabalho.

\section{REFERÊNCIAS}

ARRUDA, I. R. S. Imobilização de lectinas em membranas polissacarídicas e sua aplicação como curativo tópico. Recife: Universidade Federal de Pernambuco, 2014. (Tese de doutorado).

ELISABETSKY, E.; SOUZA, G. C. Etnofarmacologia como ferramenta na busca de sustâncias ativas. In: SIMÕES, C. M. O.; SCHENKEL, E. P.; GOSMANN, G.; MELlO, J. C. P.; MENTZ, L. A.; PETROVICK, P. R. (Org.). Farmacognosia: da planta ao medicamento. 6 ed. Porto Alegre: UFRGS; Florianópolis: UFSC, 2010. p. 107-122.

FIEDLER, N. C.; SOARES, T. S.; SILVA, G. F. Produtos florestais não madeireiros: importância e manejo sustentável da floresta. Revista Ciências Exatas e Naturais, v.10, n. 2, 2008. Disponível em: <http://revistas.unicentro.br/index.php/RECEN/article/view/712/885>. Acesso em: 23 mar. 2016.

GONDIM, A. C. S. Atividade antitumoral e antiviral de lectinas de Leguminosas (Tribo Phaseoleae, Subtribo Diocleineae): ConBr, ConM, DLasiL e DSclerL. Fortaleza: Universidade Federal do Ceará, 2014. (Tese de Doutorado).

MACEDO, F. M.; MARTINS, G. T.; MENDES, C. S. O.; SILVA, C. M.; RODRIGUES, C. G.; OLIVEIRA, D. A. Determinação de compostos fenólicos totais em barbatimão [Stryphnodendron adstringens (Mart) Coville]. Revista Brasileira de Biociências, v. 5, n. 2, p. 1164-1165, 2007. 
MONEGO, E. T.; PEIXOTO, M. R. G.; CORDEIRO, M. M.; COSTA, R. M. (In)Segurança alimentar de comunidades quilombolas do Tocantins. Segurança alimentar e nutricional, v. 17, n. 1, p. 37-47, 2010. http://dx.doi.org/10.20396/san.v17i1.8634798

PEREIRA, P. S.; OLIVEIRA, A. J.; ROCHA, H. G.; BARROS, L. M.; DRUMOND, M. A. Utilização de extratos de sementes de visgueiro, pau-d'óleo e pau-ferro para detectar a presença de lectinas através da atividade hemaglutinante com eritrócitos. Revista Saúde e Ciência, v. 3, n. 3, p. 1-10, 2014. Disponível em: <http://www.ufcg.edu.br/revistasaudeeciencia/ index.php/RSC-UFCG/article/view/168/105>. Acesso em: 23 mar. 2016.

SILVA-LÓPEZ, R. E.; SANTOS, B. C. Bauhinia forficata Link (Fabaceae). Revista Fitos Eletrônica, v. 9, n. 3, 2015. http://dx.doi.org/10.5935/2446-4775.20150018

SOARES, S. P.; VINHOLIS, A. H. C.; CASEMIRO, L. A.; SILVA, M. L. A.; CUNHA, W. R.; MARTINS, C. H. G. Atividade antibacteriana do extrato hidroalcoólico bruto de Stryphnodendron adstringens sobre microorganismos da cárie dental. Rev. odonto ciênc., v. 2, n. 23, p. 141-144, 2008.

VARGAS, S. M. Citogenética de acessos de Cratylia sp. (Fabaceae - Papilionoideae). Lavras: Universidade Federal de Lavras, 2005. (Dissertação de Mestrado). 